\title{
Letter to Editor: Medical Confidentiality: Legal and Ethical Challenges in Iran
}

\author{
Ali Banagozar Mohammadi ${ }^{1}$, Maryam Vahabzadeh²* (D) \\ 1. Department of Internal Medicine, Faculty of Medicine, Tabriz University of Medical Sciences, Tabriz, Iran. \\ 2. Medical Toxicology Research Center, Mashhad University of Medical Sciences, Mashhad, Iran.
}

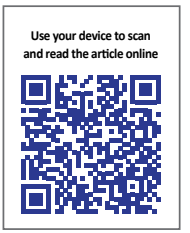

Citation: Banagozar Mohammadi A, Vahabzadeh M. Medical Confidentiality: Legal and Ethical Challengesin Iran. International Journal of Medical Toxicology and Forensic Medicine. 2020; 10(1):27024. https://doi.org/10.32598/ijmtfm.v10i1.27024

dol' $h$ ttps://doi.org/10.32598/ijmtfm.v10i1.27024

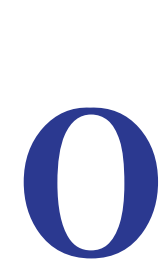

\section{Dear Editor}

$\mathrm{n}$ the matter of confidentiality, medical "secret" is an issue that physicians are aware of due to the nature of their profession. Breach of confidentiality is defined as "disclosure of a patient's medical records through different ways," such as writing, telling, implying, etc. [1,2]. According to the law in Iran, medical confidentiality is one of the principles of the medical profession and if anyone breaches it, they can be imprisoned up to one year $[3,4,5]$. Medical professionals should make every effort to protect their patients' secrets from being divulged even to their relatives. Disclosure of patients' secrets without their consent also results in public distrust in the healthcare system, which makes individuals either refusing to see the doctor or giving incomplete and inaccurate information in the future leading to serious health risks $[1,2,6]$.

However, according to the law in Iran, if the judicial authorities inquire about a patient's medical record, physicians are obliged to reveal the secret to the judge only $[4,5,7]$. Under such legislation, some exceptions dictate physicians to provide certain authorities with patients' confidential information, which are as follows [7]:

1. Reporting hazardous infectious diseases to health headquarters;
2. Providing confidential information upon written order of the judicial authority;

3. Reporting births and deaths;

4. Report of child abuse regardless of parents' consent;

5. Informing authorities of the patient's secret to protect the society; for instance, when hiding a patient's disease is potentially life-threatening harm to others;

6. Medical consultation between physicians.

Despite the aforementioned exceptions, in some cases, physicians are obliged to disclose their patients' secrets; however, there are no definite regulations, and this can be a challengeable issue for professional healthcare in Iran [8]. The most notable examples of such challenges in Iran are quoted below.

\section{Referrals from Prison}

In this case, accompanying prison guards can be a challenge. They do not leave the patient's side during visits and examinations by medical staff due to the risk of escaping [5]. Currently, due to gaps in the law, it seems that the prisoner's guards have the priority over medical staff even though their presence can interfere with proper diagnosis and treatment, which leads to possible medical errors [9]. Another challenge is when the

* Corresponding Author:

Maryam Vahabzadeh, MD, PhD.

Address: Medical Toxicology Research Centre, Mashhad University of Medical Sciences, Mashhad, Iran.

Tel: +98 (51) 38598973

E-mail:vahabzadehm@mums.ac.ir ; vahabzadehm80@gmail.com 
presence of prison guards makes them aware of not only the prisoner's medical secret but also that of other patients in the same room.

\section{Body Packers}

According to the law in Iran, possession, transportation, or purchase of narcotics is a punishable crime. In patients who raise suspicion of body packing, medical staff's efforts are pointed towards maintaining the patients' health along with ensuring the confidentiality of their information. However, due to finding illicit drugs from the patient, based on the law, hospital staff must report the case to the Drug Enforcement Administration [10].

Several years of imprisonment are the penalty for failure to report to the authorities [1]. Following the police and judicial authorities being informed about the situation, and according to the court order, the patient should be monitored by the police at the hospital until full recovery and discharge. At this time, the patient would be under custody for legal investigations. We have previously reported a similar case who was surrendered to the police for a similar reason [10].

\section{Law Ambiguity}

Dangerous infectious diseases, child abuse, birth, and death are clearly described in the law in Iran as permissible conditions to breach confidentiality. However, when it comes to disclosure of patient's secret to certain authorities to protect the physical or mental health of the society, there are ambiguities in defining life-threatening circumstances because it is not explicitly explained. This can lead to subjective interpretations and unwanted challenges when making decisions [7]. Due to the gaps in the law, doctors should act ethically and cautiously about exposing their patients' records.

\section{The Police Request Without a Court Order}

Emergency department visits due to alcohol intoxication are not uncommon in Iran. In such cases, the hospital police demand the reason for admission for documentation and reporting to the authorities. It is illegal to drink alcohol even a small amount in Iran and the consumers are penalized [5]. However, the patient's secret should not be disclosed to the lawyers or police officers. Although it may be considered illegal, alcohol use is not a reason to breach confidentiality [7].
Based on the above-mentioned challenges, Iranian physicians should avoid revealing patients' medical records without a written formal court order. It is strongly suggested that they ethically act following the confidentiality codes unless it is clarified by the law.

\section{Ethical Considerations}

\section{Compliance with ethical guidelines}

The paper is a letter to editor type of paper without involvement of any patients or third parties; therefore, no informed consents/ethical code is required.

\section{Funding}

This research did not receive any specific grant from funding agencies in the public, commercial, or not-for-profit sectors.

\section{Author's contributions}

All authors contributed in designing, running, and writing all parts of the research.

\section{Conflict of interest}

The author declared no conflict of interest.

\section{References}

[1] Tavaokkoli SN, Nejadsarvari N, Ebrahimi A. Analysis of medical confidentiality from the Islamic ethics perspective. Journal of Religion and Health. 2015; 54(2):427-34. [DOI:10.1007/s10943-013-9795-x] [PMID]

[2] Carey LB, Willis MA, Krikheli L, OBrien A. Religion, health and confidentiality: An exploratory review of the role of chaplains. Journal of Religion and Health. 2015; 54(2):676-92. [DOI:10.1007/s10943-014-9931-2] [PMID]

[3] Rieder P, Louis-Courvoisier M, Huber P. The end of medical confidentiality? Patients, physicians and the state in history. Medical Humanities. 2016; 42(3):149-54. [DOI:10.1136/medhum-2015-010773] [PMID] [PMCID]

[4] IRAN IPRCOTIRO. Law enforcement regulations for violation and misconduct of medical professionals and affiliated careers, 1999

[5] G M. Islamic [Penal Code: 2013 (Persian)]. 106 $6^{\text {th }}$ edition. Tehran, Iran: Didar Publications; 2013.

[6] Middleton J. Preventing violent extremism: The role of doctors. The Lancet. 2016; 388(10057):2219-21. [DOI:10.1016/ S0140-6736(16)31902-X] 
[7] Banagozar Mohammadi A. [Guide to common legal issues in medicine (Persian)] Tabriz University of Medical Sciences \& Shervin Publication, Tabriz; 2013.

[8] Lo S, Horton R. Legal determinants of health: Facing global health challenges. The Lancet. 2019; 4;393(10183):1781-2. [DOI:10.1016/S0140-6736(19)30808-6]

[9] Fovet T, Thomas P, Adins C, Amad A. Frances forensic psychiatry provision: The long and winding road. The Lancet Psychiatry. 2015; 2(8):e20. [DOI:10.1016/S22150366(15)00272-2]

[10] Vahabzadeh M, Banagozar Mohammadi A. Heroin bodypacking and naloxone. The Lancet. 2019; 393(10177):e35. [DOI:10.1016/S0140-6736(19)30502-1] 